\title{
P-8
}

\section{Screening of Antioxidant Activity, Phytochemical Properties and GC-MS Study of Tabernaemontana Divaricata (L.) Leaves}

\author{
Manorenjitha M.S*, Norita, A.K and Nor Mawarti, I \\ Advanced Medical and Dental Institute Universiti Sains MalaysiaBandar Putra Bertam, 13200 Kepala Batas, Penang, \\ Malaysia; E-mail: manorenjitha@amdi.usm.edu.my
}

Tabernaemontana divaricata (L.) R. Br. Ex Roem. \& Schult. which is commonly known as pinwheel plant are widely distributed in Malaysia. It is being used by the local communities for treatment of fever, pain and dysentery. The present work was designed to investigate the preliminary phytochemical, anti-oxidant and GC-MS analysis of the Tabernaemontana divaricata (double flower variety) leaves. Methanol and chloroform extracts were subjected to preliminary phytochemical screening. Subsequently, methanolic extract was selected for identification of chemical composition using the GC-MS equipped with mass detector supplied with helium while the effect of scavenging free radicals was assayed by using DPPH method with BHA as control. The methanol extract showed positive results for the presence of saponins and tannins, while chloroform extract was found to contain alkaloids, flavonoids, triterpenes and steroids. The in vitro antioxidant activity of methanol extract of Tabernaemontana divaricata leaves exhibit an $\mathrm{IC}_{50}$ of $0.31 \mathrm{mg} / \mathrm{ml}$. Based on NIST \& WILEY libraries for botanical compounds, the GC-MS analysis successfully identified 42 compounds (75-99\% matching) from the overall 129 compounds detected, which represents $54 \%$ of the chemical composition of the methanol extracts. Among the compounds identified, the 3 major compounds were neophytadiene $(8.85 \%)$, palmitic acid $(6.33 \%)$ and voacangine $(4.25 \%)$.

Keywords: Tabernaemontana divaricata, antioxidant, phytochemical, GC-MS. 